\title{
A RANDOM CHOICE, LATE DISCOVERY, AND PENALTY ROUNDS: MAPPING WOMEN'S PATHWAYS TO INFORMATION TECHNOLOGY EDUCATION
}

\author{
Hilde G. Corneliussen \\ Western Norway Research Institute, Norway
}

\begin{abstract}
What leads women to information technology (IT)? Successful recruitment is often perceived as relying on interest in IT. This study, however, identifies the pathways bringing women to IT that only partly rely on interest in IT and also involve other factors. In-depth interviews with 24 women in IT education and early research positions in Norway provide the empirical material for this qualitative study. Feminist technology studies and research on gender and technology provide a framework for the study, and the analysis is guided by the grounded theory method. The findings show that IT is a highly gendered field in Norway and that gender stereotypes affect women's expectations toward, and choices of, IT. Women enter the fields of IT despite stereotypes. However, for many such women, this follows a coincidence or a late discovery of IT as interesting, and some women have been on a "penalty round" in a different field before finally entering the fields of IT.
\end{abstract}

\section{KEYWORDS}

Educational Choices, IT Education, Women, Penalty Round, Safe Platform

\section{INTRODUCTION}

Of all the people employed in information technology (IT) jobs in Europe in 2018, more than $80 \%$ were men (EUROSTAT, 2019). The continually low proportion of women in IT has led to many studies exploring the factors that motivate women to enter the IT fields (Frieze \& Quesenberry, 2019; Makarem \& Wang, 2020). The challenge has been conceptualized as 'an 'input problem,' wherein women do not enter IT, and a 'throughput problem,' wherein women enter IT but then leave" in greater numbers than men (Branch, 2016; McKinney et al., 2008; Pantic \& Clarke-Midura, 2019). This study focuses on the first by exploring what makes women choose IT. Via analysis, five pathways leading women into IT education are identified. These pathways provide important insights about the particular ways in which women move through a landscape that they experience as unfamiliar and masculine.

This paper reports on a study conducted for the Norwegian Centre for STEM Recruitment in 2020 that aimed to build knowledge for future strategies to recruit women to the field of IT (Corneliussen, 2020, 2021). The study is based on qualitative, in-depth interviews with 24 women, students, and researchers in IT programs at science and technology faculties and universities in Norway. It is an explorative study that uses grounded theory as an analytical tool for identifying new patterns rather than relying on previous findings. Thus, the aim is not to generalize but rather to explore the variations in how women find their way into the fields of IT and to learn more about how and why these patterns develop. This paper contributes to literature in the field of gender and technology studies by expanding the knowledge of how women are recruited to fields of IT. 


\section{BACKGROUND}

Research on the low proportion of women who choose IT education and careers has been ongoing for decades and has revealed barriers and drivers for women's entry into IT (Cohoon \& Aspray, 2006; Google Inc. \& Gallup Inc., 2016; Misa, 2010). Today, there is widespread agreement that the main challenges for women's entry into IT are the institutional cultures and structures (Frieze \& Quesenberry, 2019) and the gendered stereotypes about IT (Master et al., 2016), making it a rather "bumpy road" for women (Branch, 2016). Studies from western countries have identified that youth lack knowledge about IT education and careers and that this lack of knowledge has more negative consequences for girls than for boys (Grover et al., 2014; Jethwani et al., 2016). Moreover, IT education is strongly associated with gaming and programming, making it more attractive for boys than for girls (Corneliussen, 2021; Denning \& McGettrick, 2005; Jethwani et al., 2016). Stereotypes associating IT competence more with men than with women (Blum et al., 2007; Cheryan et al., 2015) make it challenging for women to identify themselves with fields of IT (Cheryan et al., 2009; Jethwani et al., 2016; Margolis \& Fisher, 2002; OECD, 2016; Rommes et al., 2007).

This study focuses on the recruitment of women and their entry point to fields of IT. International studies suggest that the interest in and the ability-belief related to IT are important factors that are weighed more than many other factors for women's recruitment to IT (Master \& Meltzoff, 2020). Research suggests that interest in IT needs to be sparked early in girls, before gender stereotypes reduce their likeliness to express such interest (Armoni \& Gal-Ezer, 2014; DiSalvo et al., 2014). Important educational choices are made during high school, and Vainionpää et al. (2019) claim that "senior high school is the last opportunity to influence girls' major and career choice." However, studies on women attending boot camps for programming show that some women find such alternative pathways to IT more available than attending a university course (Lyon \& Green, 2020; Seibel \& Veilleux, 2019). Hyrynsalmi and Hyrynsalmi (2019) find that women also make career changes after high school to enter fields of IT and software. Thus, recent findings suggest that the ways in which men and women are recruited to IT careers may be different and that women might rely more on alternatives to traditional "college paths" (Seibel \& Veilleux, 2019). This study contributes to research in this field by exploring the pathways that bring women in Norway into fields of IT.

\section{THEORETICAL AND METHODOLOGICAL FRAMEWORK}

\subsection{Feminist Technology Studies}

This study is based on theories from feminist technology studies emphasizing gender and technology as socially constructed and co-constructed (Cockburn, 1992; Corneliussen, 2011). Gender is a reflection of the socially constructed differences between men and women, which are developed through cultural discourses and negotiated in many different arenas (Connell, 2005). Women, however, are not a uniform group, as emphasized in the individual difference theory (Trauth \& Quesenberry, 2007). This theory points to how factors such as ethnical background, age, and cultural and economic situations differentiate women from each other. Technology is also part of a gendered cultural discourse; it includes images of who work with technology, what they do, and what they know (Cheryan et al., 2015). The analysis below brings these perspectives together to explore how women navigate from early youth through the stage of high school and until entering higher IT education.

\subsection{Informants and Interviews}

This study is based on in-depth explorative interviews conducted with 24 women attending IT education programs in faculties of science and technology across different locations in Norway. The interviewees attended various IT programs, including informatics or computer science, bioinformatics, computer engineering, computer technology, cybersecurity, and business informatics. Overall, fourteen interviewees were students at bachelor level, five were students at master level, and five had a research or recruitment position in academia. Sixteen of the participants were between the ages of 20 and 24, and the average age was 27. The interviews began with a questionnaire aimed at confirming the factors identified by previous research as relevant for women's choice of entering IT education. This allowed for a more explorative interview, encouraging the interviewees to describe their experiences and explain their choices from 
childhood until they entered a university-based IT degree course. All informants are anonymized. The study has been approved by the Data Protection Services at the Norwegian Centre for Research Data.

\subsection{Grounded Theory Method}

The analysis is based on the grounded theory method inspired by Charmaz (2006). Grounded theory represents a systematic and flexible scientific method covering the entire research process, from formulating research questions to writing the analytical text (Strauss \& Corbin, 1998). Charmaz (2006) describes the method as a strategy for exploring data while answering the question: "What is going on here?" Grounded theory supports explorative research because it starts with the data and the phenomenon being studied and not with a predefined understanding. The findings presented below were obtained by coding the interview transcripts, sorting the codes and developing categories, writing analytical notes (memos), and, finally, developing the notes into scientific text. The main codes and categories developed for this study relate to the changes and movements in the women's narratives about their experiences from childhood until entering IT education and aim to answer the question, "what made the women move into IT?"

\section{FINDINGS: WOMEN'S PATHWAYS TO IT EDUCATION}

The interviews commenced with the women drawing their chronological story from youth to entering IT education (see Corneliussen, 2020). This drawing worked as a map for discussing what affected each new turn on their way through the stages from being unfamiliar with IT, to becoming interested in IT, and finally to deciding to enter the fields of IT. The discussion revealed that only few women had established an interest in IT before attending high school. The majority had developed a gradual familiarity and interest during or after high school. Interestingly, some of the women did not recognize that they had any interest in IT at all before applying for IT education. Thus, although interest in IT has been identified in international studies as one of the most important factors for the recruitment of women to IT (Master \& Meltzoff, 2020), 19 out of the 24 women interviewed in this study described other factors as more important for their entry into IT education. Furthermore, 21 women perceived IT as a masculine field before entering and expected men to dominate not only in numbers but also in terms of competence, which the women associated with boys' leisure time use of computers for playing and programming (Corneliussen, 2021). Thus, most of the women recognized IT as a highly gendered landscape. The findings shared below show how the women's pathways can be described according to the different ways of moving through this landscape. The pathways identified here are not entirely exclusive, and six women present two different pathways in their narrative (cf. Table 1 and Figure 1).

Table 1. Features defining women's pathways to IT education

\begin{tabular}{|l|l|}
\hline Pathways & Features \\
\hline 1) Early interest in IT (17\%) & $\begin{array}{l}\text { Early interest, friends with IT interest; programming, HTML, and web design; early } \\
\text { decision to study IT }\end{array}$ \\
\hline 2) Late discovery of IT (20\%) & $\begin{array}{l}\text { Limited knowledge and initially limited interest for IT; discovered IT as relevant; } \\
\text { changed direction or education into IT }\end{array}$ \\
\hline 3) An alternative platform (33\%) & $\begin{array}{l}\text { Limited knowledge and initially limited interest for IT; platform in familiar subject; } \\
\text { interest in combining IT with other fields; IT as an alternative to sciences }\end{array}$ \\
\hline 4) A random choice (20\%) & $\begin{array}{l}\text { Limited knowledge, no interest, and no intention of attending IT education before } \\
\text { suddenly finding herself there }\end{array}$ \\
\hline $\begin{array}{l}\text { 5) Invited because it suits girls } \\
\text { (10\%) }\end{array}$ & $\begin{array}{l}\text { IT culturally defined as suitable for women; mathematics as a gateway; suitable for } \\
\text { the best students }\end{array}$ \\
\hline
\end{tabular}

\subsection{Early Interest in IT}

Only five interviewed women described an early interest in IT. This interest had developed from playing with computers, coding in HTML, and learning to program. Some had started to think about studying IT already during secondary school: "I remember at secondary school, my brother asked what I wanted to be when I grew up, and I answered that I wanted to study something to do with IT. [I had] best friends who were very interested in programming, and that sort of 'infected' me too." They described the importance of IT interest 
in their environment and among friends for developing their own interest in IT. The women were interested in controlling technology because technology is important in today's society. This made programming one of the most valued skills for them to learn: "If you want to have a computer in your home, then you have to know how to use it one hundred percent. Not just two percent." One of the women had taught herself to program in high-level programming languages, such as Python and C++: "It started in high school, when friends started making video games. I was inspired and wanted to learn a little myself, since I was also playing video games. That made me want to take it to a professional 'level'." For some of these women, programming defined their interest in IT, and this also affected their educational choice; they moved directly from high school to higher IT education.

\subsection{Late Discovery of IT}

The next group of women have little knowledge of IT before they "discovered" IT as interesting. Some had this realization just in time for applying to higher education, whereas some changed their study program to IT at a later stage. Two of the women realized their interest in IT when participating in activities to recruit high school girls to IT at university level: "We were on the 'Girls days,' a conference we were invited to since we were enrolled in the science program. [...] We heard presentations by people working in IT [...]. That's when I got interested and decided that I wanted to apply."

Another woman had already decided to apply for either finance or law when she attended a presentation on IT education, and this presentation changed her mind: "I didn't think about IT as a possibility before we were supposed to apply for higher education. Back then I knew what to do [finance or law], so I just joined a friend who was going to a presentation of engineering, and that's when I found out that this was an option." Her newfound interest strengthened when she met someone working in IT, and she decided to apply to an IT program. Note that the two women described above were the only women in our sample who referred to recruitment activity organized by educational institutions as relevant for their choice of entering the IT field. Five other women "discovered" IT after they had already started at another bachelor's degree course. One of them had started at a different engineering degree course where she learned to program: "I remember, in the beginning we had programming and I did not understand the way of thinking, but I was forced to have that subject, so then I began to understand more. In the end I had a lot of fun, and that was the subject I did best. And then I wanted to change to computer science." This illustrates how interest develops after becoming familiar with IT; the interest is also related to establishing her ability-belief: recognizing that she could understand programming (Master \& Meltzoff, 2020). Several women followed this pattern. One of them fell in love with programming while learning about it through an interdisciplinary program: “I can't explain the joy I got from the introduction to programming. [...] For me, it has been one of the best things. It's like no other subject I've ever had. It was the most wonderful thing about joining that study." These narratives, however, also involve a change of direction or even a delayed entry into IT, as the women had to restart on a new degree, a phenomenon I have labeled as a "penalty round for women" (Corneliussen, 2021). Many of the interviewed women described this penalty round; they did not enter IT in the first place because they did not know enough about it when leaving high school, which suggests a missed opportunity to recruit women: "I think that since I thought IT was so much fun when I started here, I probably would have felt the same at high school." Common to the women discovering IT late is that they had little interest in IT during high school because they knew little about it. Learning about IT from a different perspective or through practice - for instance, in programming — was crucial to their discovery of IT as interesting.

\subsection{Alternative Platform}

The next group of women also had little interest in and limited knowledge about IT at high school. However, their interest had developed from a "platform" within another discipline that they already knew and had mastered. Thus, they could approach IT as a new field while ensuring professional security and with a certain level of ability-belief (Eccles, 2015). For most of these women, science was an important platform: "Mathematics was probably the strongest subject I had ever since I was a child." While feeling safe owing to the familiar platform, they could give IT a try and test whether they liked it but in combination with other subjects: "Since I looked both at biology and computer science, it was the mixture of the two that seemed interesting."

Several of the women saw IT as an alternative to a pure science program: "In high school, I had science and liked it, but I didn't like science so much that I wanted a bachelor in math or chemistry alone. [...] I saw technology as a middle ground where you could both be creative and use sciences." There was still a level of 
uncertainty in their choice due to limited exposure to IT at school; therefore, many of them initially started by considering the disciplines they already knew: "I was on the 'chemistry day,' and I was like 'no, this was kind of old-fashioned, maybe a little boring.' And then I found that program online: bioinformatics. These are two topics that I'm interested in, like the bio part and the chemical part, and you can connect it with some IT."

Although they had learned about sciences in high school, IT was new and unfamiliar, making them uncertain about the choice. However, unlike traditional science subjects, many of the women recognized IT as more relevant in today's digital society; a cybersecurity student illustrates: "I have worked with security for many years [...]. So I was interested in IT and I needed that perspective [at work]. Because it is a lot about being able to understand the digital society. [...] For me, it has been a way of preparing myself for the new digital society." The societal perspective was important for the women: "It has to do with the framework for society, in a way." One was concerned with "how we choose to set boundaries for technology [because this] will determine what society will look like in the future, including what values and what rights people will have." Although this group of women expressed various motivations for attending IT education, a common point is that they became interested in IT when they realized that it can be combined with a subject they already knew well, functioning as a safe and well-known platform for entering IT.

\subsection{A Random Choice}

Similar to the previous group, the next group had limited interest in and knowledge about IT education. They had no intention of applying for IT education — not until they, by chance, ended up in IT: "I put a list of studies in front of me, and then I just let my finger slide down and it stopped at something called [an IT degree]. I turned up at the first class; it said I had to bring my own laptop. I had minimal knowledge about that, but I went to buy myself a laptop and turned up at school and the first thing the teacher said was 'Today we will program in Visual Basic.' I had no idea what programming or Visual Basic was, so I hurried to Google it while sitting there. I understood nothing, and went to see my brother-in-law, who helped me get started with Visual Basic. And then I was really hooked after the first class. Thus, it was totally random." Her entry into IT relied on a coincidence rather than a thoughtful choice. Another woman hardly knew that she had applied to an IT program: "I didn't know anything about the discipline until I started. I didn't know I had applied for it, even; I had only searched for a lot of subjects at [university]." Her goal was to attend a particular university and therefore she had applied for any study program that seemed slightly relevant, including IT, but had since forgotten about it and was surprised when she realized she had been enrolled. A total of six women described their pathway to IT education as a result of random events rather than a deliberate choice, and they applied to IT education without identifying an interest in IT. However, once they started, most of them developed such interest, as they mentioned during the interviews, with one even becoming "hooked" to programming on the first day.

\subsection{Invited Because it Suits Girls}

"It is something cultural; it was one of the most appropriate studies for girls in [her homeland]. I knew about it because of my sister, and she encouraged me." Three women expressed a similar experience with IT education, having been "recommended and encouraged" to study IT because it was considered "appropriate for women." None of them were born in Norway. In their homeland, IT had been presented as a natural choice for students, such as them, who were good at mathematics. One of them explained that IT attracted the best students: "That is also why I chose to go to IT, because it was a trend, but also because the best students go there. I had the best results at school, and that's how I chose the direction." These women were surprised to find so few women in IT in Norway-not because of the expectations of Norwegian gender equality but because they were used to seeing more women attending IT education: "It was a shock, for me: 'Really, am I the only girl in this class?"' We do not find this pathway to IT education among the women who grew up in Norway.

\subsection{A Fragile Choice}

Whereas interest in IT is often treated as a decisive factor for both girls and boys choosing IT education (Master \& Meltzoff, 2020), the five identified pathways show that only some of the women considered interest in IT as important for their choice of entering the field of IT. The majority rather claimed that their 
pathway to IT was a coincidence or based on interest in other subjects. The women interviewed here also recognized that they had little knowledge about different IT disciplines, and only few had been encouraged in the direction of IT. For some, the unknown became a motivational factor: "It was because I thought it seemed pretty open and it seemed like you had a lot of opportunities and I just really wanted to try it out." One of the women used the motto of Pippi Longstocking (a children's book character, "the strongest girl in the world," by Astrid Lindgren) to illustrate how difficult it was to know what to expect in this unfamiliar field: "I've never done this before, so I'm probably really good at this."

Owing to the women's lack of insights about IT, several of them described IT as a fragile choice and that upon entering, they considered it a test to find out if it suited them: "After high school, when I started looking at studies, I didn't quite know what it was, but I thought it seemed interesting [...]. There wasn't much information about bioinformatics either, so I didn't really know what I was going for. [...] After all, I knew nothing about programming and computer science." Some of the women were still not certain after enrolling that IT education was right for them: "To be completely honest, I would say that I was not really interested until I started [...]. When I started here, I was a little skeptical too [...]. So it was like, ok, if I absolutely do not like it then I can always switch." The lack of knowledge about IT made entering the field of IT a fragile choice because they were prepared from the start to leave if IT did not turn out to be a good fit for them.

\section{DISCUSSION}

This study suggests that many women are not recruited to IT education through the expected route of moving from high school to university with a dedicated wish to study IT. Rather, for the majority of women in this study, their pathways to IT are characterized by the discovery of IT as relevant and interesting through other channels than those at high school. The findings suggest that although the women might initially have had low motivation to study IT, they established an interest when they realized that IT can be combined with something familiar, such as science, or something they find interesting, such as societal challenges. This finding is in line with research suggesting that a feeling of belonging is important for developing interest in IT (Master \& Meltzoff, 2020). A surprisingly large group of women, one out of four, described how they had ended up in the IT field owing to random incidents and with no initial intention of studying IT. This also illustrates the difficulty in considering IT as a relevant field of study before being confronted with it. The last pathway, taken by women from other cultures, shows that women are invited and encouraged to choose IT education partly because it is considered appropriate for women. This installs a different pathway for women's entry into IT, one that is not recognized among the women born in Norway. This pathway also helps to identify the cultural character of the Norwegian women's narratives, highlighting some of the challenges and barriers for women's decisions to attend IT education in Norway.

\section{CONCLUSION: AN INVISIBLE OPTION}

This study reminds us that women are not a unified group; they have different backgrounds and interests, and they have found different pathways to IT education that also illustrate how educational patterns are shaped by culture. Although IT education is a varied field with many different disciplines, the trend identified here shows that many young women in Norway do not see IT as a relevant educational choice while they move from high school to higher education. Women's limited knowledge about IT at this point also includes little knowledge about the different IT disciplines. Consequently, many women rely on the stereotypical images of IT before attending an IT program. This suggests that women choose IT education despite barriers, in particular, a close association between IT and men (Corneliussen, 2020). The findings show that women know few people who work in IT, they identify few female role models in IT, and only few of them are encouraged to take up IT. They have to negotiate a culture recognized for causing low self-confidence in women and challenging women's feelings of belonging in IT (Corneliussen, 2020). The long list of barriers experienced by the women suggests that the right question might not be why there are so few women in IT but rather how women, despite all the experienced barriers, still find their way into IT. The many detours and coincidences that lead women to IT education indicate a significant unused potential for recruiting women to IT. The main challenge seems to involve women's lack of experience and insights into IT during high school. We also saw that many of the women became interested in, fascinated with, and found great joy in IT and 
that several women believed that they would have become interested earlier if they had only been introduced to it. The extra round many of them go before establishing sufficient insights into IT to attend an IT program is what I have termed women's "penalty round" (Corneliussen, 2021). Paradoxically, in many ways, the detour they have taken has helped them to identify IT education as a relevant opportunity for them. The detour has not only made them better acquainted with IT but also less afraid to enter a professional field that remains deeply rooted in the cultural notions of IT as a male-dominated field.

\section{ACKNOWLEDGMENT}

The study was conducted on behalf of the Norwegian Centre for STEM recruitment in 2020. This publication was funded by Nordwit, the Nordic Centre of Excellence studying women in tech-driven careers in the Nordic countries.

\section{REFERENCES}

Armoni, M., \& Gal-Ezer, J. (2014). Early Computing Education - Why? What? When? Who? ACM Inroads, 5(4), 54-59.

Blum, L., Frieze, C., Hazzan, O., \& Dias, M. B. (2007). A Cultural Perspective on Gender Diversity in Computing. In C. J. Burger, E. G. Creamer, \& P. S. Meszaros (Eds.), Reconfiguring the Firewall. Recruiting Women to Information Technology across Cultures and Continents (109-133). Wellesley, MA: A K Peters, LTD.

Branch, E. H. (Ed.) (2016). Pathways, potholes, and the persistence of women in science: Reconsidering the pipeline. Lanham MD: Lexington Books.

Charmaz, K. (2006). Constructing grounded theory: A practical guide through qualitative research. London: Sage Publications.

Cheryan, S., Master, A., \& Meltzoff, A. N. (2015). Cultural Stereotypes as Gatekeepers: Increasing Girls' Interest in Computer Science and Engineering by Diversifying Stereotypes. Frontiers in psychology, 6(49), 1-8.

Cheryan, S., Plaut, V. C., Davies, P. G., \& Steele, C. M. (2009). Ambient Belonging: How Stereotypical Cues Impact Gender Participation in Computer Science. Journal of Personality and Social Psychology, 97(6), 1045-1060.

Cockburn, C. (1992). The circuit of technology: gender, identity and power. In R. Silverstone \& E. Hirsch (Eds.), Consuming Technologies: Media and Information in Domestic Spaces (32-47). London: Routledge.

Cohoon, J. M., \& Aspray, W. (Eds.). (2006). Women and information technology: Research on underrepresentation. Cambridge, MA: MIT Press.

Corneliussen, H. G. (2011). Gender-Technology Relations: Exploring Stability and Change. Basingstoke: Palgrave Macmillan.

Corneliussen, H. G. (2020). "Dette har jeg aldri gjort før, så dette er jeg sikkert skikkelig flink på" - Rapport om kvinner i IKT og IKT-sikkerhet. Sogndal: VF-rapport 8/2020.

Corneliussen, H. G. (2021). Women empowering themselves to fit in ICT. In E. Lechman (Ed.), Technology and Women's Empowerment. London: Routledge.

Denning, P. J., \& McGettrick, A. (2005). Recentering computer science. Communications of the ACM, 48(11), 15-19.

DiSalvo, B., Guzdial, M., \& Bruckman, A. (2014). Saving Face While Geeking Out: Video Game Testing as a Justification for Learning Computer Science. The journal of the Learning Sciences, 23(3), 272-315.

Eccles, J. S. (2015). Gendered Socialization of STEM Interests in the Family. Journal of Gender, Science and Technology, 7(2), 116-132. $\quad$ Retrieved from http://genderandset.open.ac.uk/index.php/genderandset/article/view/419/692

EUROSTAT. (2019). ICT specialists in employment: statistics explained. https://ec.europa.eu/eurostat/statisticsexplained/index.php/ICT_specialists_in_employment [Accessed 10 May 2021].

Frieze, C., \& Quesenberry, J. L. (2019). Cracking the Digital Ceiling: Women in Computing Around the World. Cambridge: Cambridge University Press.

Google Inc. \& Gallup Inc. (2016). Diversity gaps in computer science: exploring the underrepresentation of girls, Blacks and Hispanics. http://goo.gl/PG34aH [Accessed 16 June 2021].

Grover, S., Pea, R., \& Cooper, S. (2014). Remedying misperceptions of computer science among middle school students Proceedings of the 45th ACM technical symposium on Computer science education (343-348): ACM.

Hyrynsalmi, S., \& Hyrynsalmi, S. (2019). What motivates adult age women to make a career change to the software industry? 2019 IEEE International Conference on Engineering, Technology and Innovation (ICE/ITMC) (1-8): IEEE. 
Jethwani, M. M., Memon, N., Seo, W., \& Richer, A. (2016). “I Can Actually Be a Super Sleuth”: Promising Practices for Engaging Adolescent Girls in Cybersecurity Education. Journal of Educational Computing Research, 55(1), 3-25.

Lyon, L. A., \& Green, E. (2020). Women in coding boot camps: an alternative pathway to computing jobs. Computer Science Education, 30(1), 102-123.

Makarem, Y., \& Wang, J. (2020). Career experiences of women in science, technology, engineering, and mathematics fields: A systematic literature review. Human Resource Development Quarterly, 31(1), 91-111.

Margolis, J., \& Fisher, A. (2002). Unlocking the clubhouse. Women in computing. Cambridge, Mass.: MIT Press.

Master, A., Cheryan, S., \& Meltzoff, A. N. (2016). Computing Whether She Belongs: Stereotypes Undermine Girls' Interest and Sense of Belonging in Computer Science. Journal of Educational Psychology, 108(3), 424-437.

Master, A., \& Meltzoff, A. N. (2020). Cultural Stereotypes and Sense of Belonging Contribute to Gender Gaps in STEM. International of Gender, Science and Technology, 12(1), 152-198.

McKinney, V. R., Wilson, D. D., Brooks, N., O’Leary-Kelly, A., \& Hardgrave, B. (2008). Women and Men in the IT Profession. Communications of the ACM, 51(2), 81-84.

Misa, T. J. (Ed.) (2010). Gender Codes: Why Women are Leaving Computing. Hoboken, New Jersey: IEEE Computer Society and John Wiley \& Sons, Inc.

OECD. (2016). PISA 2015 results (Volume I). Excellence and equity in education. Paris: OECD Publishing.

Pantic, K., \& Clarke-Midura, J. (2019). Factors that influence retention of women in the computer science major: A systematic literature review. Journal of Women and Minorities in Science and Engineering, 25(2), 119-145.

Rommes, E., Overbeek, G., Scholte, R., Engels, R., \& De Kemp, R. (2007). 'I'm not interested in computers': Gender-based occupational choices of adolescents. Information, Communication \& Society, 10(3), 299-319.

Seibel, S., \& Veilleux, N. (2019). Factors influencing women entering the software development field through coding bootcamps vs. computer science bachelor's degrees. Journal of Computing Sciences in Colleges, 34(6), 84-96.

Strauss, A., \& Corbin, J. (1998). Basics of qualitative research: Techniques and procedures for developing grounded theory. London: Sage Publications.

Trauth, E. A., \& Quesenberry, J. L. (2007). Gender and the information technology workforce: issues of theory and practice. In P. Yoong \& S. Huff (Eds.), Managing IT Professionals in the Internet Age (18-36). Hersey, PA: Idea Group Publishing.

Vainionpää, F., Kinnula, M., Iivari, N., \& Molin-Juustila, T. (2019). Gendering and Segregation in Girls' Perceptions of IT as a Career Choice: A Nexus Analytic Inquiry. In A. Siarheyeva et al. (Eds.), Information Systems Development: Information Systems Beyond 2020 (ISD 2019 Proceedings) (1-12). Toulon, France: ISEN Yncréa Méditerranée. 